\title{
Estimation of Trunk Muscle Parameters for a Biomechanical Model by Age, Height and Weight
}

\author{
Akihiko SEO ${ }^{1}$, Joon-Hee LEE$^{2}$ and Yukinori KUSAKA ${ }^{3}$ \\ ${ }^{1}$ Department of Intelligent Systems, Graduate School of Engineering, Tokyo Metropolitan Institute of \\ Technology, ${ }^{2}$ Department of Orthopedics, Jichi Medical School and ${ }^{3}$ Department of Environmental Health, School \\ of Medicine, Fukui Medical University, Japan
}

\begin{abstract}
Estimation of Trunk Muscle Parameters for a Biomechanical Model by Age, Height and Weight: Akihiko SEO, et al. Department of Intelligent Systems, Graduate School of Engineering, Tokyo Metropolitan Institute of Technology-To establish more accurate equations for estimating the moment arm length and cross-sectional area of the erector spinae and rectus abdominis muscles, the effects of height, weight and age on those muscles were analyzed by using a high-order polynomial equation. Data on the moment arm length and cross-sectional area at L3/ 4 were obtained from MRI images of 152 males and 98 females. The statistical model used in this study has any combination of up to third-order independent variables for age, height and weight. The effective independent variables were selected by the forward step method of multiple regression analyses. The results of multiple regression analyses showed that the polynomial equations for the moment arm length of erector spinae in both genders, and that for the rectus abdominis in males, contained all three variables of age, height and weight. That for the moment arm length of female rectus abdominis contained the variables of weight and age. The multiple correlation coefficients of the erector spinae and rectus abdominis were 0.355 and 0.650 for males, 0.364 and 0.411 for females, respectively. The equations for the cross-sectional area of the erector spinae in both genders, as well as that for male rectus abdominis contained only one variable (weight). The multiple correlation coefficients of the cross-sectional area of the erector spinae were 0.576 for males and 0.469 for females. The cross-sectional area of the female rectus abdominis had no effective variables.
\end{abstract}

(J Occup Health 2003; 45: 197-201)

Received June 14, 2002; Accepted April 20, 2003

Correspondence to: A. Seo, Department of Intelligent Systems, Graduate School of Engineering, Tokyo Metropolitan Institute of Technology, 6-6, Asahigaoka, Hino, Tokyo 191-0065, Japan
Key words: Moment arm length, Cross-sectional area, Biomechanical model, Low back pain

The moment arm lengths of trunk muscles such as the erector spinae and rectus abdominis to the lumbar vertebra and the cross-sectional areas of these muscles are biomechanical parameters for estimating low back load ${ }^{1)}$. Many studies have tried to obtain precise values for these parameters $^{2-12)}$. Some of them analyzed the relationships between these parameters and physical data such as height and weight ${ }^{4,7,9,12)}$. Concerning the moment arm length of the erector spinae, for example, Reid et al. ${ }^{4)}$ found significant correlations with height and weight. McGill et $a l .{ }^{7)}$, but Tracy et $a l .{ }^{8)}$ and Chaffin et al. ${ }^{9)}$ found no significant correlations. Kumar' ${ }^{6}$ denied the effect of age on moment arm length, but Chaffin et al. ${ }^{9)}$ commented that the moment arm length does slightly lengthen with age by comparing the results of various studies on different age groups. These inconsistent effects of age and physical data on biomechanical parameters may be due to the limited age group samples ${ }^{9)}$ or the use of simple linear equations that do not include the interactions between age and physical data. In this research, we analyzed the effects of age, height and weight on the moment arm length and cross-sectional area of the erector spinae and rectus abdominis by multiple regression analysis by using a high-order polynomial equation with the interactions. We then tried to establish more accurate equations for estimating these biomechanical parameters.

\section{Subjects and Methods}

Subjects

Taking part in the study were 152 male and 98 female volunteers leading healthy daily lives in Japan. None of the subjects had ever received medical treatment for back pain. Informed consent was obtained from each subject. The subjects ranged in age from 15 to $75 \mathrm{yr}$ (mean \pm standard deviation (SD): $36.2 \pm 13.1 \mathrm{yr}$ ) for males and 16 to $65 \mathrm{yr}(39.7 \pm 9.9 \mathrm{yr})$ for females. Their height was 
from 150 to $187 \mathrm{~cm}(168.5 \pm 6.3 \mathrm{~cm})$ for males and 143 to $170 \mathrm{~cm}(155.5 \pm 5.3 \mathrm{~cm})$ for females. Their weight was from 47 to $94 \mathrm{~kg}(65.5 \pm 9.2 \mathrm{~kg})$ for males and 40 to $80 \mathrm{~kg}(54.4 \pm 6.6 \mathrm{~kg})$ for females. Their BMI (body mass index) was from 16.3 to $30.7(23.1 \pm 2.9)$ for males and 18.0 to $32.5(22.5 \pm 2.6)$ for females.

\section{Methods}

A transverse cross-sectional image of the trunk at the third to fourth lumbar vertebrae (L3/4) was taken with an MRI (MRP-20, Hitachi, Japan). From the resulting images, we manually measured both the right and left sides of the moment arm length and cross-sectional area of the muscles of the erector spinae and rectus abdominis based on the method of Reid et al. ${ }^{5)}$. The moment arm length was defined as the anterior-posterior distance between the center of the muscle and that of the vertebral body. The centers of the muscle and vertebral body were the intersections of their long and short axes assuming their cross-sectional shape to be an ellipse. The crosssectional areas were measured with a planimeter (Planex 5, Tamaya Technics Inc., Japan).

Analyses

The average of the right and left moment arm length and that of cross-sectional area of each subject were calculated for the analysis. The Pearson's correlation coefficients of age, height and weight to the moment arm length and cross-sectional area were obtained to check the simple linear correlations. The estimating polynomial equation was made by using the following statistical model:

$$
\mathrm{Y}=\sum_{i=0}^{3} \sum_{j=0}^{3} \sum_{k=0}^{3} \mathrm{C}_{i j k} \times \mathrm{A}^{i} \times \mathrm{H}^{j} \times \mathrm{W}^{k}+\varepsilon \quad-(1)
$$

where,

$\mathrm{Y}=$ moment arm length $(\mathrm{cm})$ or cross-sectional area $\left(\mathrm{cm}^{2}\right)$ (average of the values for the right and left sides)

$$
\begin{aligned}
& \mathrm{A}=\text { age }(\mathrm{yr}) \\
& \mathrm{H}=\text { height }(\mathrm{cm}) \\
& \mathrm{W}=\text { weight }(\mathrm{kg}) \\
& i, j, k=\text { integers from } 0 \text { through } 3 \\
& \mathrm{C}_{i j k}=\text { regression coefficient } \\
& \varepsilon=\text { error term of regression. }
\end{aligned}
$$

To express the non-linear effects of independent variables on dependent variables, the original statistical

\begin{tabular}{|c|c|c|c|c|c|c|c|}
\hline \multicolumn{8}{|l|}{ a) Males } \\
\hline Age (yr) & $\mathrm{N}$ & Height $(\mathrm{cm})$ & Weight (kg) & MALES (cm) & MALRA (cm) & $\operatorname{CSAES}\left(\mathrm{cm}^{2}\right)$ & CSARA $\left(\mathrm{cm}^{2}\right)$ \\
\hline$\leq 19$ & 12 & $171.6(4.2)$ & $64.8(11.3)$ & $5.26(0.55)$ & $6.10(0.97)$ & $24.6(5.2)$ & $7.43(1.91)$ \\
\hline 20-29 & 38 & $171.9(6.5)$ & $66.8(10.7)$ & $5.34(0.52)$ & $6.12(1.10)$ & $24.7 \quad(5.1)$ & $7.59(1.86)$ \\
\hline 30-39 & 48 & $170.1(4.1)$ & 67.6 (7.9) & $5.49(0.35)$ & $6.28(1.16)$ & $24.9(3.5)$ & 7.83 (1.93) \\
\hline $40-49$ & 31 & $166.1(4.7)$ & $63.2(8.3)$ & $5.38(0.44)$ & $6.45(1.24)$ & $21.7(4.0)$ & $6.92(2.19)$ \\
\hline $50-59$ & 11 & $162.4(6.7)$ & $62.9(8.0)$ & $5.54(0.56)$ & $7.01(1.62)$ & $22.8 \quad(5.8)$ & $7.20(2.61)$ \\
\hline$\geq 60$ & 12 & $160.0(3.8)$ & $61.6(7.6)$ & $5.70(0.57)$ & $6.95(1.62)$ & $23.8 \quad(4.3)$ & $6.48(1.48)$ \\
\hline Total & 152 & $168.5(6.3)$ & $65.5(9.2)$ & $5.43(0.47)$ & $6.36(1.24)$ & $23.9(4.5)$ & $7.40(2.01)$ \\
\hline \multicolumn{8}{|c|}{ b) Females } \\
\hline Age (yr) & $\mathrm{N}$ & Height $(\mathrm{cm})$ & Weight (kg) & MALES $(\mathrm{cm})$ & MALRA $(\mathrm{cm})$ & $\operatorname{CSAES}\left(\mathrm{cm}^{2}\right)$ & $\operatorname{CSARA}\left(\mathrm{cm}^{2}\right)$ \\
\hline$\leq 19$ & 2 & $166.0(0.0)$ & $63.5(3.5)$ & $4.85(0.68)$ & $4.65(0.04)$ & $18.8(5.3)$ & $5.95(1.77)$ \\
\hline 20-29 & 12 & $159.2(5.5)$ & $53.2(5.7)$ & $4.90(0.45)$ & $4.30(0.83)$ & $15.3(2.6)$ & $4.83(1.16)$ \\
\hline $30-39$ & 32 & $155.7(4.8)$ & $53.8(5.0)$ & $4.87(0.35)$ & $4.67(1.05)$ & $16.6(2.5)$ & $5.04(0.96)$ \\
\hline $40-49$ & 37 & $154.5(5.2)$ & $55.7(6.8)$ & $5.06(0.47)$ & $5.23(0.86)$ & $18.5(3.2)$ & $5.35(1.52)$ \\
\hline $50-59$ & 13 & $153.7(4.5)$ & $52.3(9.6)$ & $4.82(0.71)$ & $5.28(1.68)$ & $16.2(3.0)$ & $4.54(1.25)$ \\
\hline$\geq 60$ & 2 & $152.0(2.8)$ & $50.0(0.0)$ & $5.09(0.30)$ & $5.34(0.39)$ & $14.7 \quad(2.2)$ & $3.29(0.03)$ \\
\hline Total & 98 & $155.5(5.3)$ & 54.4 (6.6) & $4.94(0.47)$ & $4.93(1.09)$ & 17.1 & $5.05(1.30)$ \\
\hline
\end{tabular}
model (1) should contain a higher order of independent variables. The maximum order for the model was limited to three, because the total number of terms for the model must be smaller than the number of samples (98 for females).

Table 1. Mean and standard deviations of anthropometric data in each age class

MALES: moment arm length of erector spinae, MALRA: moment arm length of rectus abdominis, CSAES: cross-sectional area of erector spinae, CSARA: cross-sectional area of rectus abdominis. Numbers in parentheses indicate standard deviations. The values for cross-sectional areas are the average of the values for right and left side muscles. 
Table 2. Pearson's correlation coefficients among variables

\begin{tabular}{|c|c|c|c|c|c|c|}
\hline & \multicolumn{3}{|c|}{ Males } & \multicolumn{3}{|c|}{ Females } \\
\hline & Age & Height & Weight & Age & Height & Weight \\
\hline Height & $-0.587^{*}$ & & & $-0.420 *$ & & \\
\hline Weight & -0.146 & $0.448 *$ & & -0.034 & $0.398 *$ & \\
\hline MALES & $0.232 *$ & -0.005 & $0.250 *$ & 0.089 & $0.232 *$ & $0.276^{*}$ \\
\hline MALRA & $0.282 *$ & -0.112 & $0.491 *$ & $0.314 *$ & -0.065 & $0.205^{*}$ \\
\hline CSAES & -0.123 & $0.285^{*}$ & $0.576^{*}$ & 0.141 & 0.167 & $0.465^{*}$ \\
\hline CSARA & -0.139 & 0.107 & $0.358 *$ & -0.074 & 0.043 & 0.189 \\
\hline
\end{tabular}

MALES: moment arm length of erector spinae, MALRA: moment arm length of rectus abdominis, CSAES: cross-sectional area of erector spinae, CSARA: cross-sectional area of rectus abdominis. *: indicates statistical significance at $5 \%$.

Table 3. Equation for estimating moment arm length and cross-sectional area

\begin{tabular}{lccr}
\hline a) Males & & & \\
\hline Equation & $\mathrm{R}$ & $\mathrm{SE}$ & $\mathrm{P}$ \\
\hline MALES $(\mathrm{cm})=5.01+9.68 \times 10^{-11} \mathrm{AH}^{2} \mathrm{~W}^{2}$ & 0.355 & 0.445 & $<0.0001$ \\
MALRA $(\mathrm{cm})=5.40+3.51 \times 10^{-7} \mathrm{AW}^{3}-3.68 \times 10^{-12} \mathrm{AH}^{3} \mathrm{~W}^{2}$ & 0.650 & 0.948 & $<0.0001$ \\
CSAES $\left(\mathrm{cm}^{2}\right)=5.32+2.84 \times 10^{-1} \mathrm{~W}$ & 0.576 & 3.70 & $<0.0001$ \\
CSARA $\left(\mathrm{cm}^{2}\right)=2.26+7.85 \times 10^{-2} \mathrm{~W}$ & 0.358 & 1.88 & $<0.0001$ \\
\hline b) Females & & & \\
\hline Equation & $\mathrm{R}$ & $\mathrm{SE}$ & $\mathrm{P}$ \\
\hline MALES $\left(\mathrm{cm}^{2}=4.31-1.27 \times 10^{-9} \mathrm{~A}^{2} \mathrm{~W}^{3}+2.21 \times 10^{-12} \mathrm{AH}^{3} \mathrm{~W}^{2}\right.$ & 0.364 & 0.444 & 0.0012 \\
MALRA $\left(\mathrm{cm}^{2}=4.32+2.18 \times 10^{-9} \mathrm{~A}^{2} \mathrm{~W}^{3}\right.$ & 0.411 & 0.997 & $<0.0001$ \\
CSAES $\left(\mathrm{cm}^{2}\right)=11.36+1.912 \times 10^{-3} \mathrm{~W}^{2}$ & 0.469 & 2.73 & $<0.0001$ \\
CSARA $\left(\mathrm{cm}^{2}\right)=5.05$ & - & 1.30 & - \\
\hline
\end{tabular}

MALES: moment arm length of erector spinae, MALRA: moment arm length of rectus abdominis, CSAES: crosssectional area of erector spinae, CSARA: cross-sectional area of rectus abdominis. A: age (yrs), H: height (cm), W: weight $(\mathrm{kg})$. R: multiple correlation coefficient, SE: regression error, P: probability of significance of the regression equation.

Although the statistical model (1) contains 64 terms including one constant, the forward stepwise method for the multiple regression analyses selected only the effective terms. The F value for selecting terms was set to 4. StatView ver.5 (SAS Institute, USA) was used for the analyses.

\section{Results}

The basic statistics of the moment arm length and crosssectional area by gender and age class are shown in Table 1. The Pearson's correlation coefficients between variables are shown in Table 2 . The estimating polynomial equations obtained by multiple regression analyses are shown in Table 3.

As Table 2 shows, significant correlations were observed among age, height and weight. In addition, since some of the terms in the original statistical model (1) also had close correlations with other terms, the multiple regression analyses selected up to three effective terms, including the constant, as shown in Table 3. For males, the equation of moment arm length contained all of the variables for age, height and weight, but those of crosssectional area contained only the variable for weight. The equations for females showed more complex results. The equation for moment arm length of the erector spinae contained all of the variables for age, height and weight, but that for the cross-sectional area of the rectus abdominis had no effective terms. The effect of each variable on moment arm length is shown in Fig. 1 using the polynomial equation when the rest of variables are 
Moment arm length $(\mathrm{cm})$

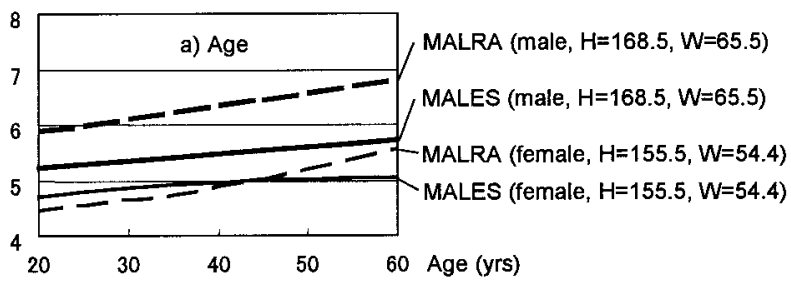

Moment arm length $(\mathrm{cm})$

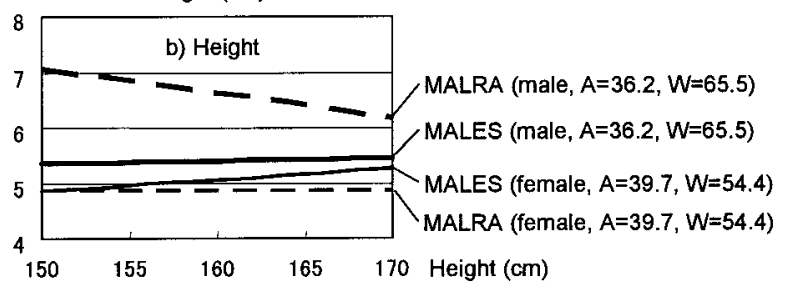

Moment arm length $(\mathrm{cm})$

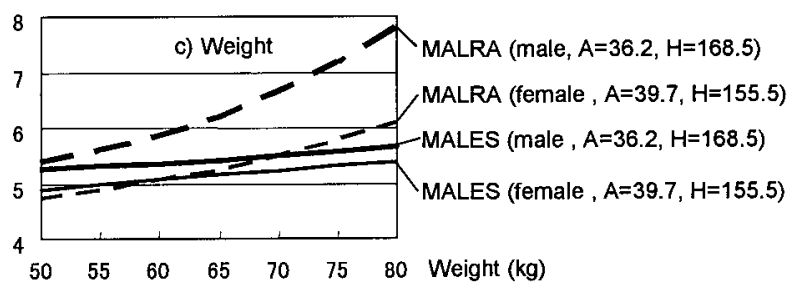

Fig. 1. Effects of age, height and weight on moment arm lengths found by using the estimating equations in Table 3. MALES: moment arm length of erector spinae, MALRA: moment arm length of rectus abdominis. A: age (yr), H: height $(\mathrm{cm}), \mathrm{W}$ : weight $(\mathrm{kg})$.

assumed to have constant mean values for each gender.

\section{Discussion}

To assess the risk of work-related low back pain, which is the most common health problem at various work sites $^{13)}$, biomechanical methods are recommended ${ }^{14)}$. According to the low back biomechanical model, the lumbar disc compression force and trunk muscle load depend on the moment arm length and cross-sectional area of trunk muscles ${ }^{1,15)}$. When considering individual differences, the effects of age and physique on the trunk muscle parameters should be clarified as much as possible. In this study, we measured the moment arm lengths and cross-sectional areas of the erector spinae and rectus abdominis of subjects across a wide age range (15 to $75 \mathrm{yr}$ ) of subjects, and analyzed the effects of the age and physique on the trunk muscle parameters. The direct effects of age, height and weight were found by simple linear models as shown in Table 2, but it was still necessary to use a high-order polynomial statistical model to clarify those non-linear and interactive effects on the trunk muscle parameters. Although the multiple correlation coefficients of the models shown in Table 3 were relatively small, like those in other papers ${ }^{7,9)}$, the equations obtained could be useful in minimizing the effect of individual differences.

As shown in Fig. 1a, the moment arm lengths of both muscles increase with age in both genders, when the height and weight are constant. Kramer et al. ${ }^{6}$ ) attributed this trend to a slackening of the muscles. The hyperplasia of bone with aging might be another reason for the elongation of the moment arm. Age was not related to the cross-sectional area for either gender. Based on these results, the reduction of back muscle strength with aging could be explained by the change in muscle quality due to aging.

Some studies have indicated that height was related to neither moment arm length nor cross-sectional area ${ }^{6,8,9)}$. Our results partially supported this indication, as shown in Table 2. The analyses using the model including polynomial interactions, but clearly indicated an effect of height on the moment arm length except for the female rectus abdominis as shown in Table 4 . Fig. $1 \mathrm{~b}$ indicated that the moment arm lengths of the erector spinae and rectus abdominis of both genders increased, but that of the rectus abdominis of males decreased with height. For the rectus abdominis, tall but slim males have shorter moment arm lengths than short and obese males as shown in Fig. $1 \mathrm{~b}$ and $1 \mathrm{c}$.

Weight was related to the moment arm length and cross-sectional area, except for the female rectus abdominis. The moment arm enlarged with weight, as shown in Fig. 1c. For the rectus abdominis, the moment arm might be elongated for overweight people because of the increase in intra-abdominal volume caused by the increase in offal fat. Wood et al. ${ }^{12)}$ showed that the relative value of the cross-sectional areas of the rectus abdominis to the trunk cross-sectional area were smaller in obese males than those in lean males. They concluded that the trunk muscles become large with weight, but this is insufficient to compensate for the load increase caused by weight.

It was found that age, height and weight affect the values for the moment arm length and the cross-sectional area of the erector spinae and rectus abdominis. According to the biomechanical model, the lumbar disc compression force increases with trunk muscle activities and body weight ${ }^{1)}$. The elongation of the moment arm length is effective in suppressing the compression force by reducing the muscle activities ${ }^{1}$. The increase in the crosssectional area of muscles, which is directly related to the increase in muscle volume, also reduces muscle activities because the higher volume muscles can generate the same contraction forces at lower muscle activities ${ }^{15)}$. The elongation of moment arm and the increase in muscle volume corresponding to the increase in height and weight will therefore contribute to compensating for the increase 
in the lumbar disc compression force and muscle load caused by the increase in body weight. The increase in moment arm length with aging will also be good for reducing low back load in the aged, although the increase may not be an effective one, as Kumer ${ }^{6)}$ pointed out. Age did not affect the cross-sectional areas of muscles, but it is widely known that the back muscles weaken with age. Therefore, although the predicted values from the equations in this research could be used for biomechanical models, it is still necessary to consider the aging effect on muscle quality such as the degeneration caused by the deposits of fat and connective tissue ${ }^{16,17)}$.

In this paper, the moment arm length and crosssectional area were measured at L3/4 because the MRI images at this level were optimal for identifying the muscle cross-sections. Kumar ${ }^{6}$ measured the moment arms of the erector spinae and rectus abdominis at the seventh thoracic vertebra (T7) to L5 by CT scans, but they found no significant differences in the lengths among the levels. Chaffin et al. ${ }^{9)}$ measured both moment arms and cross-sectional areas of the muscles at L2/3 to L4/5 by CT scans. They also found no significant differences. Therefore, the predicted values obtained with our equations are applicable to the levels from L3 to L5.

The data used in this paper were measured while the subjects were supine. McGill et al. ${ }^{18)}$ stated that the moment arm lengths of the erector spinae and rectus abdominis measured while their subjects stood were $13 \%$ and $30 \%$ longer, respectively, than while they were supine. It may be better to apply their findings when using our equations.

\section{References}

1) Chaffin DB, Andersson GBJ, Martine BJ. Occupational Biomechanics. New York: John Wiley \& Sons, 1999.

2) JG Reid and PA Costigan: Geometry of adult rectus abdominis and erector spinae muscles. J Orthop Sports Ther 6, 278-280 (1985)

3) G Ne'meth and H Ohlsen. Moment arm lengths of trunk muscles to the lumbosacral joint obtained in vivo with computed tomography. Spine 11, 158-160 (1986)

4) JG Reid, PA Costigan and W Comrie: Prediction of trunk muscle areas and moment arms by use of anthropometric measures. Spine 12, 273-275 (1987)

5) JG Reid and PA Costigan: Trunk muscle balance and muscular force. Spine 12, 783-786 (1987)
6) S Kumar: Moment arms of spinal musculature determined from CT scans. Clin Biomechanics 3, 137144 (1988)

7) SM McGill, N Patt and RW Norman: Measurement of the trunk musculature of active males using CT scan radiography: Implications for force and moment generating capacity about the L4/L5 joint. J Biomechanics 21, 329-341 (1988)

8) MF Tracy, MJ Gibson, EP Szypryt, A Rutherford and EN Corlett: The geometry of the muscles of the lumbar spine determined by magnetic resonance imaging. Spine 14, 186-193 (1989)

9) DB Chaffin, MS Redfern, M Erig and SA Goldstein: Lumbar muscle size and locations from CT scans of 96 women of age 40 to 63 years. Clin Biomech 5, 916 (1990)

10) GA Dumas, MJ Poulin, B Roy, M Gagnon and M Jovanovic: Orientation and moment arms of some trunk muscles. Spine 16, 293-303 (1991)

11) P Tveit, K Daggfeldt, S Hetland and A Thorstensson: Erector spinae lever arm length variations with changes in spinal curvature. Spine 19, 199-204 (1994)

12) S Wood, DJ Pearsall, R Ross and JG Reid: Trunk muscle parameters determined from MRI for lean to obese males. Clin Biomechanics 11, 139-144 (1996)

13) Bernard BP (ed). Musculoskeletal disorders and workplace factors. Cincinnati: U.S. Department of Health and Human Services, 1997.

14) Cohen AL, Gjessing CC, Fine WJ, Bernard BP, McGlothlin JD. Elements of ergonomics programs. Cincinnati: U.S. Department of Health and Human Services, 1997.

15) SM McGill: A myoelectrically based dynamic threedimensional model to predict loads on lumbar spine tissues during lateral bending. J Biomechanics 25, 395414 (1992)

16) R Parkkola and M Kormano: Lumbar disc and back muscle degeneration on MRI: Correlation to age and body mass. J Spinal Disorders 5, 86-92 (1992)

17) JH Lee, K Nakamura, O Yamaguchi and Y Ooi. Consideration of the trunk muscle cross-sectional area using MRI: Comparison between subjects with and without episodes of low back pain. J Phyical Med 4, 3-7 (1993) (in Japanese)

18) SM McGill, D Juker and C Axler. Correcting trunk muscle geometry obtained from MRI and CT scans of supine postures for use in standing postures. J Biomechanics 29, 643-646 (1996) 